\title{
Lymphocytes, Interleukin 6 and D-dimer Cannot Predict Clinical Outcome in Coronavirus Cancer Patients: LyNC1.20 Study
}

\author{
GIANLUCA VANNI $^{1}$, MARCO MATERAZZO ${ }^{1}$, MARIO DAURI ${ }^{2}$, ANDREA FARINACCIO ${ }^{2}$, \\ CHIARA BUONOMO ${ }^{2}$, ILARIA PORTARENA1, MARCO PELLICCIARO ${ }^{1}$, JACOPO MARIA LEGRAMANTE ${ }^{3}$, \\ STEFANO RIZZA ${ }^{4}$, CARLO CHIARAMONTE $^{2}$, ALFONSO BELLIA $^{4}$, MICHELE GRANDE $^{6}$, \\ SAVERIO POTENZA ${ }^{7}$, FRANCESCO PAOLO SBORDONE ${ }^{8}$, MARCO ALFONSO PERRONE $^{9}$, \\ FRANCESCO GRIMALDI $^{8}$, MARCELLO CHIOCCHI $^{8}$ and ORESTE CLAUDIO BUONOMO ${ }^{1}$ \\ ${ }^{1}$ Breast Unit, Department of Surgical Science, Policlinico Tor Vergata University, Rome, Italy; \\ ${ }^{2}$ Department of Emergency and Admission, Critical Care Medicine, \\ Pain Medicine and Anesthetic Science, Policlinico Tor Vergata University, Rome, Italy; \\ ${ }^{3}$ Emergency Department, Tor Vergata University Hospital, Rome, Italy; \\ ${ }^{4}$ Department of Systems Medicine, University of Rome Tor Vergata, Rome, Italy; \\ ${ }^{5}$ Department of Statistic, University of Rome Tor Vergata, Rome, Italy; \\ ${ }^{6}$ Department of General and Emergency Surgery, University of Tor Vergata, Rome, Italy; \\ ${ }^{7}$ Department of Biomedicine and Prevention, Section of Legal Medicine, \\ Social Security and Forensic Toxicology, University of Rome Tor Vergata, Rome, Italy; \\ ${ }^{8}$ Department of Biomedicine and Prevention, Division of Diagnostic Imaging, \\ University of Rome Tor Vergata, Rome, Italy; \\ ${ }^{9}$ Division of Cardiology, University of Rome Tor Vergata, Rome, Italy
}

\begin{abstract}
Background/Aim: Knowledge of Coronavirus 19 (COVID19) pathogenetic mechanisms is necessary to provide new treatment strategies. This study aims to assess how oncological disease impacts on the clinical course of COVID19 patients. Patients and Methods: From $1^{\text {st }}$ March to $30^{\text {th }}$ April 2020, 96 COVID-19 patients were classified according to clinical outcome as severe $(n=67)$ and moderate $(n=29)$. Demographic data, medical history, admission lymphocytes, procalcitonin $(P C T)$, -reactive-protein $(C R P), D$-dimer, and Interleukin-6 (IL-6) were collected. Results: A statistically significant association was found between hypertension $(p=0.007)$ and three or more comorbidities with severe outcomes $(p=0.034)$. No statistical differences were found between the
\end{abstract}

This article is freely accessible online.

Correspondence to: Gianluca Vanni, Breast Unit, Department of Surgical Science, Policlinico Tor Vergata University, Viale Oxford 81, 00133 Rome, Italy. Tel: +39 3395685883, e-mail: vanni_gianluca@yahoo.it

Key Words: Coronavirus, COVID-19, oncology, immunology, Cancer, Il-6, D-dimer, lymphocyte. severe and moderate groups with regards to the rate of patients with past oncological history. However, no patient allocated in the moderate group had received oncological treatment within 12 months. Higher values of CRP, IL-6, D-Dimer and lower values of lymphocytes were reported in the severe group ( $p=0.0007, p=0.00386, p=0.041$, and $p=0.007$, respectively). Using binary logistic regression, higher values of CRP $(O R=8.861 ; p=0.012)$ and PCT were associated with a higher risk of severe outcome $(O R=21.075 ; p=0.008)$. Within the oncological population, D-Dimer and IL-6 did not confirm their prognostic significance as in the general population $(p>0.05)$. Conclusion: Specific prognostic factors for oncological patients should be designed for COVID-19 clinical practice.

The Coronavirus-19 (COVID-19) pandemic represents a global challenge due to the rapid spread and poor prognosis, with a fatality rate of $6.2 \%$ and more than 5 million people infected worldwide (1). COVID-19 has strongly impacted all medical science fields and several physicians are currently reorganizing their clinical practice in order to provide the best treatment and reduce the risk of cross contamination (24). Based on the most recent flu pandemic, the Center for Infectious Disease Research and Policy (CIDRAP) calculated that this outbreak will likely last up to 24 months (1). In 
view of this, each national health system should focus their efforts not only on COVID-19 treatment, but also on reorganizing elective programs (5), ensuring the psychosocial well-being of the population (6-8).

In order to provide a treatment for COVID-19, several clinical trials for drugs and vaccine development are ongoing worldwide (9-11). Following the temporary pause of the hydroxychloroquine arm within the Solidarity trial $(9,12)$, detailed knowledge of pathogenetic mechanisms is even more urgent for designing a correct treatment for COVID-19 patients $(13,14)$. Some authors advocate a link between a subset of COVID-19 patients and the cytokine storm, as seen in syndromes like Secondary haemophagocytic lymphohistiocytosis (13). However, immunosuppression therapy in these patients could be a difficult decision and its possible benefits should be carefully weighed against its possible detrimental effects (14).

In common clinical practice, several conditions have been linked with immune system impairment, including iatrogenic, within the postoperative period $(15,16)$, after allograft surgery $(17,18)$ or in cancer $(19)$. Concerning the latter, ample evidence proves that neoplastic lesions are under immunosurveillance $(20,21)$. Initially, innate and adaptive immune responses are able to control tumor growth (22). In this phase-elimination, acute inflammatory responses triggered by tumor-associated 'danger signals' initiates tumor cell recognition leading to secretion of proinflammatory cytokines and activation of the innate immune cells [e.g. natural killer cells, dendritic cells (DC) and macrophages]. Upon maturation, DCs migrate to nearby lymph nodes, where they present tumor antigens and activate tumor specific CD4+ and CD8+ lymphocytes. Recent studies demonstrate that these immune cells are indeed mounting an antitumor response which could eventually determine cancer immmunosurveillance (23-26). That said, tumor progression is a multistep complex cascade (19), which requires evasion from the host's immunosurveillance mechanisms (27) and immunoediting eventually resulting in short or long term distant relapse (28-30). Due to the novelty of the COVID-19 outbreak, there is a lack of evidence regarding the complex relationship between altered immunological status and the COVID-19 disease in oncological patients (13, 14, 28, 29). Theoretically, oncological preexistent immunosuppression could harm or benefit different subsets of COVID-19 patients, reducing the cytokine storm or further complicating the disease course $(13,14)$.

The aim of our study was to assess how oncological disease could impact on the clinical course of COVID-19 patients in our monocentric Italian cohort, and the prognostic value of blood test administration in our oncological population.

\section{Patients and Methods}

Patients. From $1^{\text {st }}$ March to $30^{\text {th }}$ April 2020, 96 patients were retrospectively enrolled in the study. The local institutional review board of Fondazione Policlinico tor Vergata approved the LYnC1.20 study (CEI $\left.n^{\circ} 121 / 20\right)$. The inclusion criteria were the following: nasal or oropharyngeal swab positive for COVID19, admission due to suspected symptoms in the Tor Vergata University Hospital or transfer from other facilities with a COVID-19 diagnosis. Exclusion criteria were absence of blood tests or patients who underwent surgery during hospitalization.

After admission, all patients were treated with hydroxychloroquine or chloroquine, with or without a macrolide or were enrolled in one of several clinical trials ongoing in our institution. Some patients also received glucocorticoid and/or intravenous immunoglobulin. All therapies were administered according to the clinical data and the medical evidence available during the clinical course of the disease. Distinct COVID-19 respiratory management strategies were applied to severe patients according to disease phenotypes, including prone positioning.

Data collection. All clinical data were obtained from clinical notes. Age at diagnosis, sex and date of hospitalization were recorded. Date of first symptoms onset was collected for calculating the time from onset of symptoms to hospitalization. Cough, fever, asthenia, headache, dyspnea and any digestive or ocular symptoms were recorded in the analysis as first symptoms (31-33).

The patients' clinical presentations were classified into the severe group and moderate group. Patients were enlisted in the severe group if a severe event occurred during any time of hospitalization. Severe events were defined as admission to the intensive care unit requiring invasive ventilation, breathing support with non-invasive ventilation (NIV) with oxygen administration more than $30 \%$, or death. Patients without any of these events were classified into the moderate group. All past non oncological patient medical history was recorded in order to underline all preexisting medical conditions. All medical conditions were considered as dichotomous variables. Cardiovascular diseases, such as hypertension and ischemic heart disease were analyzed separately. Personal history of cancer was recorded and analyzed separately. In the oncological population, all previous treatments administered within 12 months prior to COVID-19 diagnosis were recorded and divided according to radiation oncology, systemic or surgical treatment.

Blood test. Admission blood tests were included in the study: lymphocytes count, procalcitonin (PCT), c reactive protein (CRP), D-dimer and interleukin-6 (IL-6). Most admission blood tests were collected in our emergency department, while some were performed in external facilities. When tests were not available, patients were excluded from the study.

Statistical analysis. All data were imported into Excel (Microsoft, Washington, DC, USA). According to the sample, continuous variables were reported as median and interquartile range (IQR) and the Mann-Whitney $U$-test was used to compare different groups. Past medical conditions were treated as dummy variables. Categorical variables were reported as number plus percentage and Fisher's exact test was applied. Binary Multivariate regression analysis was carried out and continuous variables were transformed into dummy variables using median values as cutoff. Wald Backward stepwise selection was performed. Variables with assigned $p$-Value $<0.05$ were considered statistically significant. All statistical analyses were performed with SPSS version 26 (SPSS Inc., Chicago, IL, USA). 
Table I. Demographic and patient history characteristics.

\begin{tabular}{|c|c|c|c|c|}
\hline Variable & $\begin{array}{l}\text { All patients } \\
\quad(\mathrm{n}=96)\end{array}$ & $\begin{array}{l}\text { Severe group } \\
\quad(n=67)\end{array}$ & $\begin{array}{l}\text { Moderate group } \\
\qquad(\mathrm{n}=29)\end{array}$ & $p$-Value \\
\hline Median age in years (IQR) & $65.0(55.8-75.0)$ & $65.5(56.0-76.0)$ & $61.0(53.0-76.3)$ & 0.878 \\
\hline Median time from symptom onset to hospitalization in days (IQR) & $5(3-7)$ & $4(3-7)$ & $6(3-8)$ & 0.235 \\
\hline \multicolumn{5}{|l|}{ Gender } \\
\hline Male & $68(70.83 \%)$ & $49(73.34 \%)$ & $19(65.52 \%)$ & \multirow[t]{2}{*}{0.471} \\
\hline Female & $28(29.17 \%)$ & $18(26.86 \%)$ & $10(34.48 \%)$ & \\
\hline \multicolumn{5}{|l|}{ First diagnosis in Tor Vergata University Hospital } \\
\hline Yes & $76(79.16 \%)$ & $59(88.06 \%)$ & $17(89.66 \%)$ & \multirow[t]{2}{*}{0.710} \\
\hline No & $20(20.83 \%)$ & $8(11.94 \%)$ & $3(10.34 \%)$ & \\
\hline \multicolumn{5}{|l|}{ Cardiovascular risk factor } \\
\hline \multicolumn{5}{|l|}{ Myocardial Infarction } \\
\hline Yes & $17(17.71 \%)$ & $8(11.94 \%)$ & $9(31.03 \%)$ & \multirow[t]{2}{*}{0.039} \\
\hline No & $79(82.29 \%)$ & $59(88.06 \%)$ & $20(68.97 \%)$ & \\
\hline \multicolumn{5}{|l|}{ Hypertension } \\
\hline Yes & $28(29.17 \%)$ & $34(50.75 \%)$ & $6(20.69 \%)$ & \multirow[t]{2}{*}{0.007} \\
\hline No & $39(70.83 \%)$ & $33(49.25 \%)$ & $23(79.31 \%)$ & \\
\hline \multirow{2}{*}{\multicolumn{5}{|c|}{$\begin{array}{l}\text { Non oncological comorbidities } \\
\geq 1\end{array}$}} \\
\hline & & & & \\
\hline Yes & $64(66.67 \%)$ & $49(73.14 \%)$ & $15(51.72 \%)$ & \multirow[t]{2}{*}{0.037} \\
\hline No & $32(33.33 \%)$ & $18(26.86 \%)$ & $14(48.27 \%)$ & \\
\hline \multicolumn{5}{|l|}{$\geq 2$} \\
\hline Yes & $32(33.33 \%)$ & $26(38.81 \%)$ & $6(26.09 \%)$ & \multirow[t]{2}{*}{0.082} \\
\hline No & $64(66.67 \%)$ & $41(61.19 \%)$ & $23(73.91 \%)$ & \\
\hline \multicolumn{5}{|l|}{$\geq 3$} \\
\hline Yes & $15(15.82 \%)$ & $14(20.90 \%)$ & $1(3.45 \%)$ & \multirow[t]{2}{*}{0.034} \\
\hline No & $81(81.48 \%)$ & $53(79.10 \%)$ & $28(96.55 \%)$ & \\
\hline \multicolumn{5}{|l|}{$\geq 4$} \\
\hline Yes & $9(9.38 \%)$ & $9(13.43 \%)$ & $0(0 \%)$ & \multirow[t]{2}{*}{0.053} \\
\hline No & $87(90.62 \%)$ & $58(86.57 \%)$ & $29(100 \%)$ & \\
\hline \multicolumn{5}{|l|}{ Oncological comorbidities } \\
\hline \multicolumn{5}{|l|}{ Personal cancer history } \\
\hline Yes & $16(16.67 \%)$ & $12(17.91 \%)$ & $4(13.79 \%)$ & \multirow[t]{2}{*}{0.796} \\
\hline No & $80(83.33 \%)$ & $55(82.09 \%)$ & $25(86.21 \%)$ & \\
\hline
\end{tabular}

All continuous variables are reported as median and interquartile range (IQR) within brackets; categorical data are reported as frequency and percentage within brackets. $p$-Values are calculated with Fisher's exact test for categorical variables and Mann-Whitney $U$-test for continuous variables.

\section{Results}

Demographic and anamnestic data. 96 COVID-19 patients treated in Tor Vergata University Hospital were included in the study, which was comprised of $68(70.83 \%)$ males and $28(29.17 \%)$ females. The median age was 65.0 (55.8-75.0) years. According to clinical data, 67 patients were enlisted in the severe group and 29 in the moderate group. All data are summarized in Table I.

No statistical difference was found between the moderate and the severe groups when compared in terms of age $(p=0.878)$ or sex $(p=0.471)$. Cases were subdivided according to patient admission; 76 (79.17\%) patients received COVID-19 diagnosis in Tor Vergata hospital, 20 (20.83\%) were admitted to Tor Vergata COVID-Hospital after diagnosed in other facilities. No statistically significant differences were found between the moderate and severe group in the rate of diagnosis obtained in Tor Vergata Hospital $(p=0.710)$. The duration of symptoms until hospitalization was not found to be statistically significant between the groups ( $p=0.235$ ), even though the severe group exhibited a lower value when compared to the moderate group (4 vs. 6 days, respectively).

Personal history. Oncological comorbidities. Personal history of patients was analyzed (Table I). No statistically significant distribution was found between previous the personal cancer history and clinical course $(p=0.770) .16$ $(16.67 \%)$ and $4(13.79 \%)$ patients with previous cancer history were enlisted in the severe and moderate group, respectively.

Among 12 patients enlisted in the severe group, 2 (16.67\%) cases of prostate cancer, $4(33.33 \%)$ cases of lymphoma, 1 
$(8.33 \%)$ case of testicular cancer, $1(8.33 \%)$ case of upper airway cancer, $1(8.33 \%)$ case of lung cancer, $1(8.33 \%)$ case of colorectal cancer and $1(8.33 \%)$ case of cholangiocarcinoma were recorded. Finally, in $1(8.33 \%)$ case of the severe group cancer was suspected breast cancer. Among 4 patients in the moderate group, $1(25.00 \%)$ case of prostate cancer, $1(25.00 \%)$ case of gastric cancer, $1(25.00 \%)$ case of lung cancer and 1 $(25.00 \%)$ case of colon cancer were recorded. All cancer treatment was recorded if performed within the 12 months prior to COVID-19 diagnosis.

In the severe group, 3 (25.00\%) patients underwent surgery (tracheostomy, surgical resection of cholangiocarcinoma and radical prostatectomy) and $2(12.5 \%)$ patients received systemic treatment for hemopoietic malignancies. In the moderate group, none of the patients underwent surgery and no systemic treatment was administered. In both cases, distribution among the groups failed to reach a statistical significance (oncological treatment $p=0.234$; surgical treatment $p=0.517$; medical treatment $p=1.000$ ). In both groups, no oncological radiation therapy was administered within 12 months.

Other comorbidities. Cardiovascular comorbidities were analyzed (Table I). In the moderate group, a higher rate of hypertension was recorded with $34(50.75 \%)$ cases, when compared to the severe group with 6 cases $(20.69 \%)$, a statistically significant difference $(p=0.007)$. Conversely, a lower rate of myocardial infarction was registered in the moderate group when compared to the severe group with 8 $(11.94 \%) v s .9(31.03 \%)$, respectively $(p=0.039)$. In order to assess the role of non-oncological comorbidities in the clinical outcome, all comorbidities were recorded as dummy variables.

Comparing moderate and severe groups, patients in the moderate group had a lower number of comorbidities, as displayed in Table I. Moreover, statistically significant distribution was found classifying the patients with 1 or more comorbidities and three or more comorbidities $(p=0.037$ and 0.034 , respectively).

\section{Blood test}

General population. The absolute number of lymphocytes, PTC, CRP, D-Dimer and IL-6 upon admission are enlisted in Table II. The severe group showed lower values for lymphocyte counts, compared to the moderate group $(p=0.0007)$.

Conversely, higher values of PTC and CRP were detected in the severe group when compared to the moderate group. CPR upon admission demonstrated a statistically significant difference between the groups $(p=0.00386)$ with median values of 123.6 and 28.8 in the severe and moderate groups, respectively. PCT values upon admission reached 0.23 in the severe group and 0.05 in the moderate group without a statistically significant difference $(p=0.149)$.
Moreover, the severe group showed higher admission values of D-dimer and IL-6 (1344 and 325.5, respectively) when compared to the moderate group (888 and 31.8, respectively). Both variables resulted in statistically significant differences $(p=0.0412$ for D-Dimer and $p=0.007$ for IL-6 value).

Oncological population. Subsequently, blood sample analysis was performed only in the oncological population $(n=16)$, as shown in Table III. The severe group exhibited lower absolute values of lymphocytes when compared to the moderate group, in concordance with our cohort. However, no statistically significant differences were found among the oncological population $(p=0.917)$.

The severe oncological population showed higher values of CPR when compared to the moderate group (11.85 vs. 11.85 , respectively) and statistically significant differences between groups were registered $(p=0.037)$. However, the PCT did not show a statistically significant difference in the oncological analysis between the groups, similarly to the general COVID-19 population.

Finally, oncological population analysis failed to find a statistically significant distribution between outcome (severe $v s$. moderate group) and D-Dimer and IL-6 ( $p=0.580$ and 0.259 , respectively). D-dimer median values were higher in the moderate oncological group, as reported in Table III.

Binary multivariate regression. Results of binary multivariate regression are displayed in Table IV. In our cohort, myocardial infarction represented a protective factor for severe outcome $(\mathrm{OR}=0.070)$. Conversely, higher values of CPR and PCT were associated with a higher risk of severe outcome (OR=8.861 and 21.075, respectively).

\section{Discussion}

The COVID-19 outbreak represents an emerging global health problem $(5,34,35)$. Although lockdown policies prevented health system collapse in several countries (36), the CIDRAP group expects a second wave during the fall, similarly to the 1918 Spanish flu (1). In view of this risk, identifying the at-risk population for worst outcome is essential in order to correctly address all the health care resources and to predict higher risk patients.

Cancer microenvironment is represented by heterogeneous cancer cells and their interactions with stromal cells and the immune system $(37,38)$. Tumor progression is a multistep complex cascade (19) which requires evasion from the host's immunosurveillance mechanisms (27). Immunoediting could eventually result in short or long term distant relapse (28, 29). In order to reduce the treatment immunological impairment, several medical and surgical strategies have been implemented in clinical practice $(15,16,39-41)$. 
Table II. Admission blood sample in the general population.

\begin{tabular}{lcccc}
\hline Variable & $\begin{array}{c}\text { All patients } \\
(\mathrm{n}=96)\end{array}$ & $\begin{array}{c}\text { Severe group } \\
(\mathrm{n}=67)\end{array}$ & $\begin{array}{c}\text { Moderate group } \\
(\mathrm{n}=29)\end{array}$ & $p$-Value \\
\hline Lymphocyte count (IQR) & $970(620-1220)$ & $800(557.7-1090)$ & $1110(830-1400)$ & 0.0007 \\
CRP admission (IQR) & $95.6(37.93-174.93)$ & $123.6(65.2-204.55)$ & $28.8(7.425-90.4)$ & 0.00386 \\
PCT admission (IQR) & $0.15(0.06-1.35)$ & $0.23(0.09-1.69)$ & $0.05(0.0325-0.0825)$ & 0.14977 \\
D-Dimer (IQR) & $1190.5(779.75-2419)$ & $1344(925-3898)$ & $888(453-1708)$ & 0.0412 \\
IL-6 (IQR) & $55.4(23-563)$ & $325.5(39.05-1613.5)$ & $31.8(12.9-65.25)$ & 0.007 \\
\hline
\end{tabular}

Continuous variables are reported as median and interquartile range (IQR) within brackets. CRP: C-reactive protein; PCT: procalcitonin; IL-6: interleukin-6. $p$-Values are calculated using Mann-Whitney $U$-test.

Table III. Admission blood sample and previous treatment within 12 months in the oncological population.

\begin{tabular}{|c|c|c|c|c|}
\hline Variable & $\begin{array}{c}\text { Oncological } \\
\text { patients }(n=16)\end{array}$ & $\begin{array}{l}\text { Oncological severe } \\
\text { group }(\mathrm{n}=12)\end{array}$ & $\begin{array}{l}\text { Oncological moderate } \\
\text { group }(n=4)\end{array}$ & $p$-Value \\
\hline Lymphocyte count (IQR) & $650.00(545.00-1087.50)$ & $645.00(495.00-1142.50)$ & $820.00(615.00-1035.00)$ & 0.917 \\
\hline CRP (IQR) & 98.55 (50.65-129.95) & $111.85(88.40-153.15)$ & $18.15(9.65-42-18)$ & 0.037 \\
\hline PCT & $0.15(0.12-0.28)$ & $0.15(0.11-0.28)$ & $0.09(0.06-0.14)$ & 0.542 \\
\hline D-Dimer & $1566.00(731.00-2271.00)$ & $1566.00(731.00-2259.00)$ & $1622.00(921.75-2835.75)$ & 0.580 \\
\hline IL-6 & $38.50(12.15-52.15)$ & $40.70(20.00-1557.75)$ & $12.90(11.68-21.00)$ & 0.259 \\
\hline $\begin{array}{l}\text { Previous oncological treatment } \\
\text { within } 12 \text { months }\end{array}$ & $\begin{array}{c}\text { Oncological } \\
\text { patients } n=16\end{array}$ & $\begin{array}{l}\text { Severe group } \\
\mathrm{n}=12\end{array}$ & $\begin{array}{l}\text { Moderate group } \\
n=4\end{array}$ & \\
\hline \multicolumn{5}{|l|}{ Oncological treatment } \\
\hline Yes & $6(37.50 \%)$ & $6(50 \%)$ & $0(0 \%)$ & 0.2335 \\
\hline No & $10(63.50 \%)$ & $6(50 \%)$ & $4(100 \%)$ & \\
\hline \multicolumn{5}{|l|}{ Surgical treatment } \\
\hline Yes & $4(25.00 \%)$ & $4(33.33 \%)$ & $0(0 \%)$ & 0.5165 \\
\hline No & $12(75.00 \%)$ & $8(66.66 \%)$ & $4(100 \%)$ & \\
\hline \multicolumn{5}{|l|}{ Medical treatment } \\
\hline Yes & $2(12.50 \%)$ & $2(16.67 \%)$ & $0(0 \%)$ & 1.000 \\
\hline No & $14(87.50 \%)$ & $10(83.33 \%)$ & $4(100 \%)$ & \\
\hline
\end{tabular}

Continuous variables are reported as median and interquartile range (IQR) within brackets. CRP: C-reactive protein; PCT: procalcitonin; IL-6: interleukin-6. $p$-Values are calculated using the Mann-Whitney $U$-test.

Table IV. Binary multivariable regression.

\begin{tabular}{lcccc}
\hline Variables & Median value & $\beta$ coefficient & Odds ratio (95\% CI) & $p$-Value \\
\hline Myocardial infarction & - & -2.654 & $0.070(0.006-0.828)$ & 0.035 \\
CRP & 95.6 & 2.182 & $8.861(1.6717-48.542)$ & 0.012 \\
PCT & 0.15 & 3.048 & $21.075(2.215-200.561)$ & 0.008 \\
\hline
\end{tabular}

CRP: C-reactive protein; PCT: procalcitonin. 95\% CI: 95\% confidence interval.

A nationwide analysis from Lancet Oncology predicted a higher risk for severe outcome in cancer survivors (42). However, other authors have highlighted certain limitations including a statistically significant difference between age among the groups analyzed and the low incidence of cancer in the evaluated population (43). The aim of our study was to assess the role of cancer on the COVID-19 short term outcome and the prognostic value of blood tests upon 
admission in the oncological population, according to the respiratory support need.

Demographic and anamnestic data. Our population was well matched for age and sex between the severe and moderate groups. Age is a well-known risk factor for severe outcome in COVID-19 disease (44) along with male sex (43). Despite the lack of statistical significance, higher age and higher rate of male patients were reported in our data in the severe group.

The time from onset of symptoms to hospitalization did not result in a statistically significant difference between the severe and moderate group ( $p>0.05)$, and was comparable to data reported from literature (45). Before data collection, we postulated that the severe group population could have worse prognosis due to the supportive treatment delay. However, the severe group exhibited shorter time intervals when compared to the moderate group, as reported by Chen et al. (45).

\section{Personal history}

Oncological comorbidities. Among our total sample, 16 (16.67\%) patients had a previous history of neoplasm and a higher rate of oncological patients were enrolled in the severe group (severe group vs. moderate group; $17.91 \%$ vs. $13.79 \%$, respectively), but no statistically significant difference was found between the groups $(p=0.796)$. However, past oncological history represented a risk factor for hospitalization, when the past oncological history is compared with the Italian general population prevalence of cancer history (5.3\%) (46).

Among the oncological population, sub analysis showed no statistically significant differences between previous oncological treatments within 12 months and severe presentation (surgical treatment $v s$. medical treatment; $p=0.517$ and 1.000 , respectively). Despite the lack of statistically significance, no patient with a history of oncological treatment within 12 months was registered in the moderate group. These results underline the plausible role of previous oncological treatment within 12 months as a risk factor of severe outcome.

Our results were in partial contrast with the nationwide analysis by Liang et al. $(42,47)$. The analysis included 18 patients among 1590 COVID-19 patients from 575 hospitals in 31 provincial regions and reported a higher risk of severe outcome and a higher risk of COVID-19 diagnosis in oncological patients $(42,43)$.

These differences can be accounted in part to the different prevalence among the two populations as well as the mean age $(42,47,48)$. The Italian Cancer registry reported a higher value of cancer incidence ( 730.0 per 100,000 people) when compared with data from the Chinese national registry (285.83 per 100,000 population) $(46,49)$. Furthermore, in Italy $5.3 \%$ of the general population has received a cancer diagnosis during their lifetime, compared with $0.0055 \%$ of the 5-year cancer prevalence in the Chinese Population (46,
50). With this in mind, the difference in oncological prevalence may play a role in this result. In our opinion, different disease prevalence should be considered during health facilities planning, especially when data with different disease distributions are applied in a different population.

Moreover, the analysis reported statistical significant differences in age between the oncological and nononcological groups, which could eventually have influenced the results (42-44).

Other comorbidities. Cardiovascular diseases are widely known in the literature as a risk factor of severe COVID-19 (51). Moreover, the cytokine storm and Angiotensinconverting enzyme 2 (ACE2) receptor virus tropism could cause acute heart injury $(33,51,52)$. In our population, a statistically significant association between hypertension and severe clinical presentation was reported $(p=0.007)$.

Conversely, a higher rate of myocardial infarction was found in the moderate group compared to the severe group (31.03\% vs. $11.94 \% ; p=0.034)$. This difference can be accounted for due to the lack of stratification in the myocardial infarction group and a higher hospitalization rate of patients with past history of myocardial infarction, regardless of clinical symptoms or signs.

Patients with myocardial infarction history exhibited a shorter time from onset of symptoms to hospitalization (6.22 vs. 3.57 days; $p=0.046$ ). Myocardial infarction represents a risk factor for hospitalization in COVID-19 patients as confirmed in our analysis (51). In fact, the myocardial infarction rate in the hospitalized population $(17.7 \%)$ was higher when compared to the prevalence of myocardial infarction in the Italian population $(1.8 \%$; 95\% $\mathrm{CI}=1.4-2.2)(53)$.

Multiple comorbidities were associated with severe COVID-19 $(44,54)$ and this data was confirmed by our series. A higher rate of comorbidities was reported in the severe group. Interestingly, no patient with 4 or more comorbidities was reported in the moderate group.

\section{Blood test}

General population. Theories on COVID-19 pathogenic mechanisms shifted from a "pure" Acute Respiratory Distress Syndrome to a systemic thromboembolic disease (55). Lymphopenia is an effective and reliable indicator of the severity and hospitalization in COVID-19 patients, due to the direct cytotoxic effect or the disease-induced cytokine storm (56). In our series, the prognostic role of the lymphocyte count was concordant with literature, with higher values of lymphocytes in the moderate group.

CRP levels upon admission reflects the COVID19 disease severity and should be used as a key indicator for disease monitoring (57). In our population, higher levels of CRP were associated with severe outcome. Conversely, PCT levels didn't reach a statistically significant relationship. This data is largely 
confirmed in the literature, underlying the role of PCT in the prediction of secondary bacterial infections (58).

In addition, abnormal IL-6 levels have been previously reported in the literature for COVID-19 patients (59) and blockade of IL-6 pathways with Tocilizumab has been utilized in clinical trials (60). As reported in the literature, the severe group exhibited higher values of IL-6 levels when compared with the moderate group $(p=0.007)$. Finally, higher D-dimer levels upon admission have been linked to a higher risk of in-hospital mortality (61); and an association between higher D-dimer values and a severe outcome was confirmed in our population.

Oncological population. Interestingly, the admission blood tests' prognostic role was only partially confirmed in the oncological population. Despite a lower lymphocyte count being reported in the oncologically severe group, the Mann Whitney $U$-test failed to show a statistically significant difference between the groups.

Moreover, PCT, D-dimer and IL-6 did not reach statistical significance between the groups. Only the CRP admission level showed a similar pattern to the general population, with a significantly higher value in the severe group.

These unexpected results could be explained by the complex interactions between the hosts' immune system and tumor cells $(19,27)$. Peripheral immune alterations in cancer patients was firstly recognized in the literature in 1974 by Bone and Lauder for gastrointestinal tumors (62). In particular, lymphopenia has been widely associated with advanced disease in several tumor types (27) and PCT levels have been analyzed in cancer patients as a new biomarker for prostate cancer $(63,64)$.

Oncological disease progression has been extensively linked to the IL-6 family, with high up-regulation in many cancers $(65,66)$. Even abnormal CRP levels have been linked with poor prognosis, cancer progression and patients without clinical symptoms of cancer $(67,68)$.

Despite the small cohort, preexistent immunological impairment of oncological patients seems to affect the host immune reaction towards SARS-CoV-2. In our opinion, previous oncological history should be taken into account by physicians during emergency department admission, when blood tests are commonly requested to obtain information on patients' clinical outcome.

Binary multivariate regression. In our cohort, binary multivariate regression demonstrated a protective role of myocardial infarction $(\mathrm{OR}=0.070)$. As previously mentioned, we believe that this difference could be accounted for due to the lack of stratification in the myocardial infarction group (STEMI vs. non-STEMI) and higher rate of patient hospitalization with past history of myocardial infarction regardless of clinical symptoms or signs (51).
Conversely, from the univariate analysis, a value of PCT higher than the median population constituted a risk factor for severe outcome $(\mathrm{OR}=21.075)$. PCT is a well-known marker for bacterial infection and this value could eventually predict bacterial superinfection and a subsequent worse clinical outcome $(58,59)$. Finally, the relationship between higher CRP values and severe outcome has been largely reported in literature $(57,59)$, a finding confirmed by our analysis $(\mathrm{OR}=8.861)$.

Our study contains some limitations. Firstly, the retrospective design could have influenced our data, yet study groups were well matched with regards to age, sex and duration from first symptoms to hospitalization. Moreover, the Italian COVID-19 outbreak represented an acute emerging problem and no prospective observational trial was planned before the pandemic. Secondly, no data regarding admission CT, clinical stage and lung injury was obtained from the clinical records. This choice was made in order to assess the role of well-known immunological variables on clinical outcome, which was evaluated only through the clinical course. Thirdly, no data were reported regarding the long term outcome and fatality rate in the population. In this case, we decided to perform the analysis according to the need of ventilation support, due to the gravity of a shortage during a potential second wave in the next fall, as during the first outbreak. Finally, due to the monocentric design of the study, another limitation is the sample size and further analyses with larger groups are required in order to confirm our preliminary results.

However, if confirmed by larger series, our data reflect how oncological patients are an at-risk population for hospitalization and severe outcome. All these findings confirm the role of comorbidities and preexistent immunological impairment in severe COVID-19. However, in our analysis, IL-6, PCT and lymphocyte count failed to predict the clinical outcome in oncological COVID-19 patients. Further studies are needed to design specific prognostic factors for oncological patients in COVID-19 clinical practice.

\section{Conflicts of Interest}

The Authors declare no conflicts of interest regarding this study.

\section{Authors' Contributions}

Study conception and design: Gianluca Vanni, Marco Materazzo, Marco Pellicciaro, Oreste Claudio Buonomo. Acquisition of data: Saverio Potenza, Francesco Paolo Sbordone, Francesco Grimaldi, Marcello Chiocchi Jacopo Maria Legramante, Mario Dauri, Andrea Farinaccio, Chiara Buonomo. Analysis of data: Carlo Chiaramonte, Marco Materazzo; Interpretation of data: Gianluca Vanni, Ilaria Portarena, Oreste Claudio Buonomo; Article draft: Pelliccaro Marco, Marco Materazzo. Critical revision: Michele Grande, 
Stefano Rizza, Alfonso Bellia, Buonomo Oreste Claudio. Critical Revision of Literature: Oreste Claudio Buonomo, Marco Materazzo, Marco Pellicciaro.

\section{Acknowledgements}

This study was funded with the non-conditional contribution of the Italian Ministry of Health.

The Authors sincerely acknowledge all the health care workers involved in the COVID-19 pandemic.

\section{References}

1 Moore KA, Lipsitch M, Barry JM and Osterholm MT: COVID-19: The CIDRAP Viewpoint: Part 1: The Future of the COVID-19 Pandemic: Lessons Learned from Pandemic Influenza. CIDRAP Univ Minnesota, 2020. Available at: https://www.cidrap.umn.edu/ sites/default/files/public/downloads/cidrap-covid19-viewpointpart1_0.pdf [Last accessed on May 31, 2020]

2 Buonomo OC, Materazzo M, Pellicciaro M, Caspi J, Piccione E and Vanni G: Tor Vergata University-Hospital in the beginning of COVID-19-era: Experience and recommendation for breast cancer patients. In Vivo 34: 1661-1665, 2020. PMID: 32503826. DOI: 10.21873 /invivo. 11958

3 Zhang Y and Xu JM: Medical diagnosis and treatment strategies for malignant tumors of the digestive system during the outbreak of novel coronavirus pneumonia. Zhonghua Zhong Liu Za Zhi 42: E005, 2020. PMID: 32112549. DOI: 10.3760/cma.j.cn 112152-20200227-00141

4 Repici A, Maselli R, Colombo M, Gabbiadini R, Spadaccini M, Anderloni A, Carrara S, Fugazza A, Di Leo M, Galtieri PA, Pellegatta G, Ferrara EC, Azzolini E and Lagioia M: Coronavirus (COVID-19) outbreak: what the department of endoscopy should know. Gastrointest Endosc 92: 192-197, 2020. PMID: 32179106. DOI: 10.1016/j.gie.2020.03.019

5 Vanni G, Pellicciaro M, Materazzo M, Palombi L and Buonomo OC: Breast cancer diagnosis in coronavirus-era: Alert from Italy. Front Oncol 10: 938, 2020. PMID: 32574281. DOI: 10.3389/fonc. 2020.00938

6 Vanni G, Materazzo M, Pellicciaro M, Ingallinella S, Rho M, Santori F, Cotesta M, Caspi J, Makarova A, Pistolese CA and Buonomo OC: Breast cancer and COVID - 19: The effect of fear on patients' decision-making process. In Vivo 34: 1651-1659, 2020. PMID: 32503825. DOI: 10.21873 /invivo.11957

7 Vanni G, Materazzo M, Santori F, Pellicciaro M, Costesta M, Orsaria P, Cattadori F, Pistolese CA, Perretta T, Chiocchi M, Meucci R, Lamacchia F, Assogna M, Caspi J, Granai AV, DE Majo A, Chiaravalloti A, D'Angelillo MR, Barbarino R, Ingallinella S, Morando L, Dalli S, Portarena I, Altomare V, Tazzioli $\mathrm{G}$ and Buonomo OC: The effect of coronavirus (COVID19) on breast cancer teamwork: A multicentric survey. In Vivo 34 : 1685-1694, 2020. PMID: 32503830. DOI: 10.21873/invivo.11962

8 Nickell LA: Psychosocial effects of SARS on hospital staff: survey of a large tertiary care institution. Can Med Assoc J 170: 793-798, 2004. PMID: 14993174. DOI: 10.1503/cmaj.1031077

9 Mehra MR, Desai SS, Ruschitzka F and Patel AN: Retracted: Hydroxychloroquine or chloroquine with or without a macrolide for treatment of COVID-19: a multinational registry analysis. Lancet, 2020. PMID: 32450107. DOI: 10.1016/S0140-6736(20)31180-6.
10 Richardson P, Griffin I, Tucker C, Smith D, Oechsle O, Phelan A, Rawling M, Savory E and Stebbing J: Baricitinib as potential treatment for 2019-nCoV acute respiratory disease. Lancet 395: e30-e31, 2020. PMID: 32032529. DOI: 10.1016/S01406736(20)30304-4

11 Chiricozzi A, Faleri S, Saraceno R, Bianchi L, Buonomo O, Chimenti S and Chimenti MS: Tofacitinib for the treatment of moderate-to-severe psoriasis. Expert Rev Clin Immunol 11: 443455, 2015. PMID: 25666451. DOI: 10.1586/1744666X.2015. 1013534

12 World Health Organization (WHO): Solidarity clinical trial for COVID-19 treatments. Available at: https://www.who.int/ emergencies/diseases/novel-coronavirus-2019/global-research-onnovel-coronavirus-2019-ncov/solidarity-clinical-trial-for-covid-19treatments [Last accessed on May 31, 2020]

13 Mehta P, McAuley DF, Brown M, Sanchez E, Tattersall RS and Manson JJ: COVID-19: consider cytokine storm syndromes and immunosuppression. Lancet 395: 1033-1034, 2020. PMID: 32192578. DOI: 10.1016/S0140-6736(20)30628-0.

14 Remuzzi A and Remuzzi G: COVID-19 and Italy: what next? Lancet 395: 1225-1228, 2020. PMID: 32178769. DOI: 10.1016/S0140-6736(20)30627-9.

15 Vanni G, Materazzo M, Perretta T, Meucci R, Anemona L, Buonomo C, DAURI M, Granai A V, Rho M, Ingallinella S, Tacconi F, Ambrogi V, Chiaravalloti A, Schillaci $\mathrm{O}$ and Buonomo OC: Impact of awake breast cancer surgery on postoperative lymphocyte responses. In Vivo 33: 1879-1884, 2019. PMID: 31662515. DOI: 10.21873/invivo.11681

16 Mineo TC, Sellitri F, Vanni G, Gallina FT and Ambrogi V: Immunological and inflammatory impact of non-intubated lung metastasectomy. Int J Mol Sci 18: 1466, 2017. PMID: 28686211. DOI: 10.3390/ijms18071466

17 Pisani F, Buonomo O, Iaria G, Iorio B, Rizzello A, Pollicita S, De Luca L, Valeri M, Boffo V, Famulari A and Casciani CU: Sirolimus in kidney transplantation from marginal donors. Transplant Proc 36: 495-496, 2004. PMID: 15110569. DOI: 10.1016/j.transproceed.2004.02.011

18 Piazza A, Adorno D, Poggi E, Borrelli L, Buonomo O, Pisani F, Valeri M, Torlone N, Camplone C, Monaco PI, Fraboni D and Casciani CU: Flow cytometry crossmatch: a sensitive technique for assessment of acute rejection in renal transplantation. Transplant Proc 30: 1769-1771, 1998. PMID: 9723274. DOI: 10.1016/s0041-1345(98)00423-0

19 Janssen LME, Ramsay EE, Logsdon CD and Overwijk WW: The immune system in cancer metastasis: friend or foe? J Immunother cancer 5: 79, 2017. PMID: 29037250. DOI: 10.1186/s40425-017-0283-9

20 Hanahan D and Weinberg RA: Hallmarks of cancer: The next generation. Cell 144: 646-674, 2011. PMID: 21376230. DOI: 10.1016/j.cell.2011.02.013

21 Ferroni P, Palmirotta R, Spila A, Martini F, Formica V, Portarena I, Del Monte G, Buonomo O, Roselli M and Guadagni F: Prognostic value of carcinoembryonic antigen and vascular endothelial growth factor tumor tissue content in colorectal cancer. Oncology 71: 176-184, 2006. PMID: 17652942. DOI: $10.1159 / 000106072$

22 Marzocchella L, Sini V, Buonomo O, Orlandi A, Masuelli L, Bonanno E, Lista F, Turriziani M, Manzari V, Roselli M, Modesti A and Bei R: Spontaneous immunogenicity of ribosomal $\mathrm{P} 0$ protein in patients with benign and malignant 
breast lesions and delay of mammary tumor growth in P0vaccinated mice. Cancer Sci 102: 509-515, 2011. PMID: 21175994. DOI: 10.1111/j.1349-7006.2010.01814.x

23 Vinay DS, Ryan EP, Pawelec G, Talib WH, Stagg J, Elkord E, Lichtor T, Decker WK, Whelan RL, Kumara HMCMCS, Signori E, Honoki K, Georgakilas AG, Amin A, Helferich WG, Boosani CS, Guha G, Ciriolo MR, Chen S, Mohammed SI, Azmi AS, Keith WN, Bilsland A, Bhakta D, Halicka D, Fujii H, Aquilano K, Ashraf SS, Nowsheen S, Yang X, Choi BK and Kwon BS: Immune evasion in cancer: Mechanistic basis and therapeutic strategies. Semin Cancer Biol 35: S185-S198, 2015. PMID: 25818339. DOI: 10.1016/j.semcancer.2015.03.004

24 Roselli M, Guadagni F, Buonomo O, Belardi A, Ferroni P, Diodati A, Anselmi D, Cipriani C, Casciani CU, Greiner J and Schlom J: Tumor markers as targets for selective diagnostic and therapeutic procedures. Anticancer Res 16: 2187-2192, 1996. PMID: 8694541.

25 Bielli A, Bernardini R, Varvaras D, Rossi P, Di Blasi G, Petrella G, Buonomo OC, Mattei M and Orlandi A: Characterization of a new decellularized bovine pericardial biological mesh: Structural and mechanical properties. J Mech Behav Biomed Mater 78: 420426, 2018. PMID: 29223730. DOI: 10.1016/j.jmbbm.2017.12.003

26 Buonomo O, Cabassi A, Guadagni F, Piazza A, Felici A, Piccirillo R, Atzei GP, Cipriani C, Schiaroli S, Mariotti S, Guazzaroni MN, Cossu E, Simonetti G, Pernazza E, Casciani $\mathrm{CU}$ and Roselli M: Radioguided-surgery of early breast lesions. Anticancer Res 21: 2091-2097, 2001. PMID: 11501831.

27 Dunn GP, Old LJ and Schreiber RD: The immunobiology of cancer immunosurveillance and immunoediting. Immunity 21: 137-148, 2004. PMID: 15308095. DOI: 10.1016/j.immuni.2004.07.017

28 Santori F, Vanni G, Buonomo OC, De Majo A, Rho M, Granai AV, Pellicciaro M, Cotesta M, Assogna M, D'Angelillo RM and Materazzo M: Ulcerated breast cancer with single brain metastasis: A combined surgical approach. Clinical presentation at one year follow up - A case report. Int J Surg Case Rep 73: 75-78, 2020. PMID: 32650258. DOI: 10.1016/j.ijscr.2020.06.074

29 Ielpo B, Mazzetti C, Venditti D, Buonomo O and Petrella G: A case of metachronous splenic metastasis from renal cell carcinoma after 14 years. Int J Surg 8: 353-355, 2010. PMID: 20438874. DOI: $10.1016 /$ j.ijsu.2010.04.006

30 Ielpo B, Pernaute AS, Elia S, Buonomo OC, Valladares LD, Aguirre EP, Petrella G and Garcia AT: Impact of number and site of lymph node invasion on survival of adenocarcinoma of esophagogastric junction. Interact Cardiovasc Thorac Surg 10: 704708, 2010. PMID: 20154347. DOI: 10.1510/icvts.2009.222778

31 Jin X, Lian JS, Hu JH, Gao J, Zheng L, Zhang YM, Hao SR, Jia HY, Cai H, Zhang XL, Yu GD, Xu KJ, Wang XY, Gu JQ, Zhang SY, Ye CY, Jin CL, Lu YF, Yu X, Yu XP, Huang JR, Xu KL, Ni Q, Yu CB, Zhu B, Li YT, Liu J, Zhao H, Zhang X, Yu L, Guo YZ, Su JW, Tao JJ, Lang GJ, Wu XX, Wu WR, Qv TT, Xiang DR, Yi P, Shi D, Chen Y, Ren Y, Qiu YQ, Li LJ, Sheng J and Yang Y: Epidemiological, clinical and virological characteristics of 74 cases of coronavirus-infected disease 2019 (COVID-19) with gastrointestinal symptoms. Gut 69, 2020. PMID: 32213556. DOI: 10.1136/gutjnl-2020-320926

32 Aiello F, Gallo Afflitto G, Mancino R, Li JPO, Cesareo M, Giannini C and Nucci C: Coronavirus disease 2019 (SARS-CoV2) and colonization of ocular tissues and secretions: a systematic review. Eye 34: 1206-1211, 2020. PMID: 32425362. DOI: 10.1038/s41433-020-0926-9
33 Huang C, Wang Y, Li X, Ren L, Zhao J, Hu Y, Zhang L, Fan G, Xu J, Gu X, Cheng Z, Yu T, Xia J, Wei Y, Wu W, Xie X, Yin W, Li H, Liu M, Xiao Y, Gao H, Guo L, Xie J, Wang G, Jiang R, Gao Z, Jin Q, Wang $\mathrm{J}$ and Cao B: Clinical features of patients infected with 2019 novel coronavirus in Wuhan, China. Lancet 395: 497-506, 2020. PMID: 31986264. DOI: 10.1016/S0140-6736(20)30183-5

34 Rosenbaum L: Facing Covid-19 in Italy - ethics, logistics, and therapeutics on the epidemic's front line. N Engl J Med 382: 1873-1875, 2020. PMID: 32187459. DOI: 10.1056/NEJMp 2005492

35 Vergano M, Bertolini G, Giannini A, Gristina G, Livigni S, Mistraletti G and Petrini F: Clinical Ethics Recommendations for the Allocation of Intensive Care Treatments in exceptional, resource-limited circumstances., 2020. Available at: http://www.siaarti.it/SiteAssets/News/COVID19 - documenti SIAARTI/SIAARTI - Covid-19 - Clinical Ethics Reccomendations.pdf [Last accessed on March 21, 2020]

36 Lau H, Khosrawipour V, Kocbach P, Mikolajczyk A, Schubert J, Bania $\mathrm{J}$ and Khosrawipour T: The positive impact of lockdown in Wuhan on containing the COVID-19 outbreak in China. J Travel Med, 2020. PMID: 32181488. DOI: 10.1093/jtm/taaa037

37 Noorbakhsh J, Zhao ZM, Russell JC and Chuang JH: Treating cancer as an invasive species. Mol Cancer Res 18: 20-26, 2020. PMID: 31527151. DOI: 10.1158/1541-7786.MCR-19-0262

38 Ferroni P, Roselli M, Spila A, D’Alessandro R, Portarena I, Mariotti S, Palmirotta R, Buonomo O, Petrella G and Guadagni F: Serum sE-selectin levels and carcinoembryonic antigen mRNA-expressing cells in peripheral blood as prognostic factors in colorectal cancer patients. Cancer 116: 2913-2921, 2010. PMID: 20336782. DOI: 10.1002/cncr.25094

39 Calì Cassi L, Biffoli F, Francesconi D, Petrella G and Buonomo $\mathrm{O}$ : Anesthesia and analgesia in breast surgery: the benefits of peripheral nerve block. Eur Rev Med Pharmacol Sci 21: 13411345, 2017. PMID: 28387892.

40 Buonomo O, Granai A, Felici A, Piccirillo R, De Liguori Carino N, Guadagni F, Polzoni M, Mariotti S, Cipriani C, Simonetti G, Cossu E, Schiaroli S, Altomare V, Cabassi A, Pernazza E, Casciani $\mathrm{C}$ and Roselli M: Day-surgical management of ductal carcinoma in situ (Dcis) of the breast using wide local excision with sentinel node biopsy. Tumori J 88: S48-S49, 2002. PMID: 12365390. DOI: $10.1177 / 030089160208800342$.

41 Quaranta V, Manenti G, Bolacchi F, Cossu E, Pistolese CA, Buonomo OC, Carotenuto L, Piconi C and Simonetti G: FEM analysis of RF breast ablation: multiprobe versus cool-tip electrode. Anticancer Res 27: 775-784, 2007. PMID: 17465202.

42 Liang W, Guan W, Chen R, Wang W, Li J, Xu K, Li C, Ai Q, Lu W, Liang H, Li S and He J: Cancer patients in SARS-CoV-2 infection: a nationwide analysis in China. Lancet Oncol 21: 335337, 2020. PMID: 32066541. DOI: 10.1016/S1470-2045(20) 30096-6.

43 Xia Y, Jin R, Zhao J, Li W and Shen H: Risk of COVID-19 for patients with cancer. Lancet Oncol 21: e180, 2020. PMID: 32142622. DOI: 10.1016/S1470-2045(20)30150-9

44 Bialek S, Boundy E, Bowen V, Chow N, Cohn A, Dowling N, Ellington S, Gierke R, Hall A, MacNeil J, Patel P, Peacock G, Pilishvili T, Razzaghi H, Reed N, Ritchey M and Sauber-Schatz E: Severe outcomes among patients with coronavirus disease 2019 (COVID-19) - United States, February 12-March 16, 2020. MMWR Morb Mortal Wkly Rep 69: 343-346, 2020. PMID: 32214079. DOI: 10.15585/mmwr.mm6912e2 
45 Chen J, Qi T, Liu L, Ling Y, Qian Z, Li T, Li F, Xu Q, Zhang Y, Xu S, Song Z, Zeng Y, Shen Y, Shi Y, Zhu T and Lu H: Clinical progression of patients with COVID-19 in Shanghai, China. J Infect 80: e1-e6, 2020. PMID: 32171869. DOI: 10.1016/j.jinf .2020.03.004

46 Associazione Italiana di Oncologia Medica: I numeri del cancro in Italia, 2019. Available at: https://www.aiom.it/wpcontent/uploads/2019/09/2019_Numeri_Cancro-operatoriweb.pdf [Last accessed on October 24, 2019]

47 Xia Y, Jin R, Zhao J, Li W and Shen H: Risk of COVID-19 for cancer patients. Lancet Oncol, 2020. PMID: 32142622. DOI: 10.1016/S1470-2045(20)30150-9

48 Ferlay J, Colombet M, Soerjomataram I, Mathers C, Parkin DM, Piñeros M, Znaor A and Bray F: Estimating the global cancer incidence and mortality in 2018: GLOBOCAN sources and methods. Int J Cancer 144: 1941-1953, 2019. PMID: 30350310. DOI: 10.1002/ijc.31937

49 Zheng RS, Sun KX, Zhang SW, Zeng HM, Zou XN, Chen R, Gu $\mathrm{XY}$, Wei WW and He J: Report of cancer epidemiology in China, 2015. Zhonghua Zhong Liu Za Zhi 41: 19-28, 2019. PMID: 30678413. DOI: 10.3760/cma.j.issn.0253-3766.2019.01.005

50 Bray F, Ferlay J, Soerjomataram I, Siegel RL, Torre LA and Jemal A: Global cancer statistics 2018: GLOBOCAN estimates of incidence and mortality worldwide for 36 cancers in 185 countries. CA Cancer J Clin 68: 394-424, 2018. DOI: $10.3322 /$ caac. 21492

51 Zheng Y-Y, Ma Y-T, Zhang J-Y and Xie X: COVID-19 and the cardiovascular system. PMID: 32139904. DOI: 10.1038/s41569020-0360-5

52 Wong CK, Lam CWK, Wu AKL, Ip WK, Lee NLS, Chan IHS, Lit LCW, Hui DSC, Chan MHM, Chung SSC and Sung JJY: Plasma inflammatory cytokines and chemokines in severe acute respiratory syndrome. Clin Exp Immunol 136: 95-103, 2004. PMID: 15030519. DOI: 10.1111/j.1365-2249.2004.02415.x

53 Istituto Superiore di Sanità (ISS): Progetto Cuore - Dati su rischio cardiovascolare sulla popolazione italiana. Available at: http://www.cuore.iss.it/indagini/CuoreData [Last accessed on June 29, 2020]

54 Li X, Xu S, Yu M, Wang K, Tao Y, Zhou Y, Shi J, Zhou M, Wu B, Yang Z, Zhang C, Yue J, Zhang Z, Renz H, Liu X, Xie J, Xie $\mathrm{M}$ and Zhao J: Risk factors for severity and mortality in adult COVID-19 inpatients in Wuhan. J Allergy Clin Immunol, 2020. PMID: 32294485. DOI: 10.1016/j.jaci.2020.04.006

55 Robba C, Battaglini D, Ball L, Patroniti N, Loconte M, Brunetti I, Vena A, Giacobbe DR, Bassetti M, Rocco PRM and Pelosi P: Distinct phenotypes require distinct respiratory management strategies in severe COVID-19. Respir Physiol Neurobiol 279: 103455, 2020. PMID: 32437877. DOI: 10.1016/j.resp.2020.103455

56 Tan L, Wang Q, Zhang D, Ding J, Huang Q, Tang YQ, Wang Q and Miao $\mathrm{H}$ : Lymphopenia predicts disease severity of COVID19: a descriptive and predictive study. Signal Transduct Target Ther 5: 33, 2020. PMID: 32296069. DOI: 10.1038/s41392-0200148-4

57 Wang L: C-reactive protein levels in the early stage of COVID19. Med Mal Infect 50: 332-334, 2020. PMID: 32243911. DOI: 10.1016/j.medmal.2020.03.007

58 Lippi G and Plebani M: Procalcitonin in patients with severe coronavirus disease 2019 (COVID-19): A meta-analysis. Clin Chim Acta 505: 190-191, 2020. PMID: 32145275. DOI: 10.1016/j.cca.2020.03.004
59 Liu F, Li L, Xu M, Wu J, Luo D, Zhu Y, Li B, Song X and Zhou $\mathrm{X}$ : Prognostic value of interleukin-6, C-reactive protein, and procalcitonin in patients with COVID-19. J Clin Virol 127: 104370, 2020. PMID: 32344321. DOI: 10.1016/j.jcv.2020.104370

60 Toniati P, Piva S, Cattalini M, Garrafa E, Regola F, Castelli F, Franceschini F, Airò P, Bazzani C, Beindorf EA, Berlendis M, Bezzi M, Bossini N, Castellano M, Cattaneo S, Cavazzana I, Contessi GB, Crippa M, Delbarba A, De Peri E, Faletti A, Filippini M, Frassi M, Gaggiotti M, Gorla R, Lanspa M, Lorenzotti S, Marino R, Maroldi R, Metra M, Matteelli A, Modina D, Moioli G, Montani G, Muiesan ML, Odolini S, Peli E, Pesenti S, Pezzoli MC, Pirola I, Pozzi A, Proto A, Rasulo FA, Renisi G, Ricci C, Rizzoni D, Romanelli G, Rossi M, Salvetti M, Scolari F, Signorini L, Taglietti M, Tomasoni G, Tomasoni LR, Turla F, Valsecchi A, Zani D, Zuccalà F, Zunica F, Focà E, Andreoli L and Latronico N: Tocilizumab for the treatment of severe COVID-19 pneumonia with hyperinflammatory syndrome and acute respiratory failure: A single center study of 100 patients in Brescia, Italy. Autoimmun Rev 19: 102568, 2020. PMID: 32376398. DOI: 10.1016/j.autrev.2020.102568

61 Zhang L, Yan X, Fan Q, Liu H, Liu X, Liu Z and Zhang Z: Ddimer levels on admission to predict in-hospital mortality in patients with Covid-19. J Thromb Haemost, 2020. PMID: 32306492. DOI: $10.1111 /$ jth.14859

62 Bone $\mathrm{G}$ and Lauder I: Cellular immunity, peripheral blood lymphocyte count and pathological staging of Tumours in the gastrointestinal tract. Br J Cancer 30: 215-221, 1974. PMID: 4451626. DOI: $10.1038 /$ bjc. 1974.184

63 Canat L, Atalay HA, Can O, Alkan İ and Ötünçtemur A: Serum procalcitonin levels in prostate cancer: A new biomarker? Urologia 85: 46-50, 2018. PMID: 30043712. DOI: $10.1177 / 0391560317752600$

64 Avrillon V, Locatelli-Sanchez M, Folliet L, Carbonnaux M, Perino E, Fossard G, Desseigne M, Freymond N, Geriniere L, Perrot E, Souquet P-J and Couraud S: Lung cancer may increase serum procalcitonin level. Infect Disord - Drug Targets 15: 57-63, 2015. PMID: 25809625. DOI: 10.2174/1871526515666150320162950

65 Nguyen DP, Li J and Tewari AK: Inflammation and prostate cancer: The role of interleukin 6 (IL-6). BJU Int 113: 986-992, 2014. PMID: 24053309. DOI: 10.1111/bju.12452

66 Taniguchi K and Karin M: IL-6 and related cytokines as the critical lynchpins between inflammation and cancer. Semin Immunol 26: 54-74, 2014. PMID: 24552665. DOI: 10.1016/ j.smim.2014.01.001

67 Iivanainen S, Ahvonen J, Knuuttila A, Tiainen S and Koivunen JP: Elevated CRP levels indicate poor progression-free and overall survival on cancer patients treated with PD-1 inhibitors. ESMO Open 4: e000531, 2019. PMID: 31555483. DOI: 10.1136/esmoopen-2019-000531

68 Ham M and Moon A: Inflammatory and microenvironmental factors involved in breast cancer progression. Arch Pharm Res 36: 1419-1431, 2013. PMID: 24222504. DOI: 10.1007/s12272013-0271-7

Received November 6, 2020

Revised December 5, 2020

Accepted December 14, 2020 